Provided for non-commercial research and education use. Not for reproduction, distribution or commercial use.

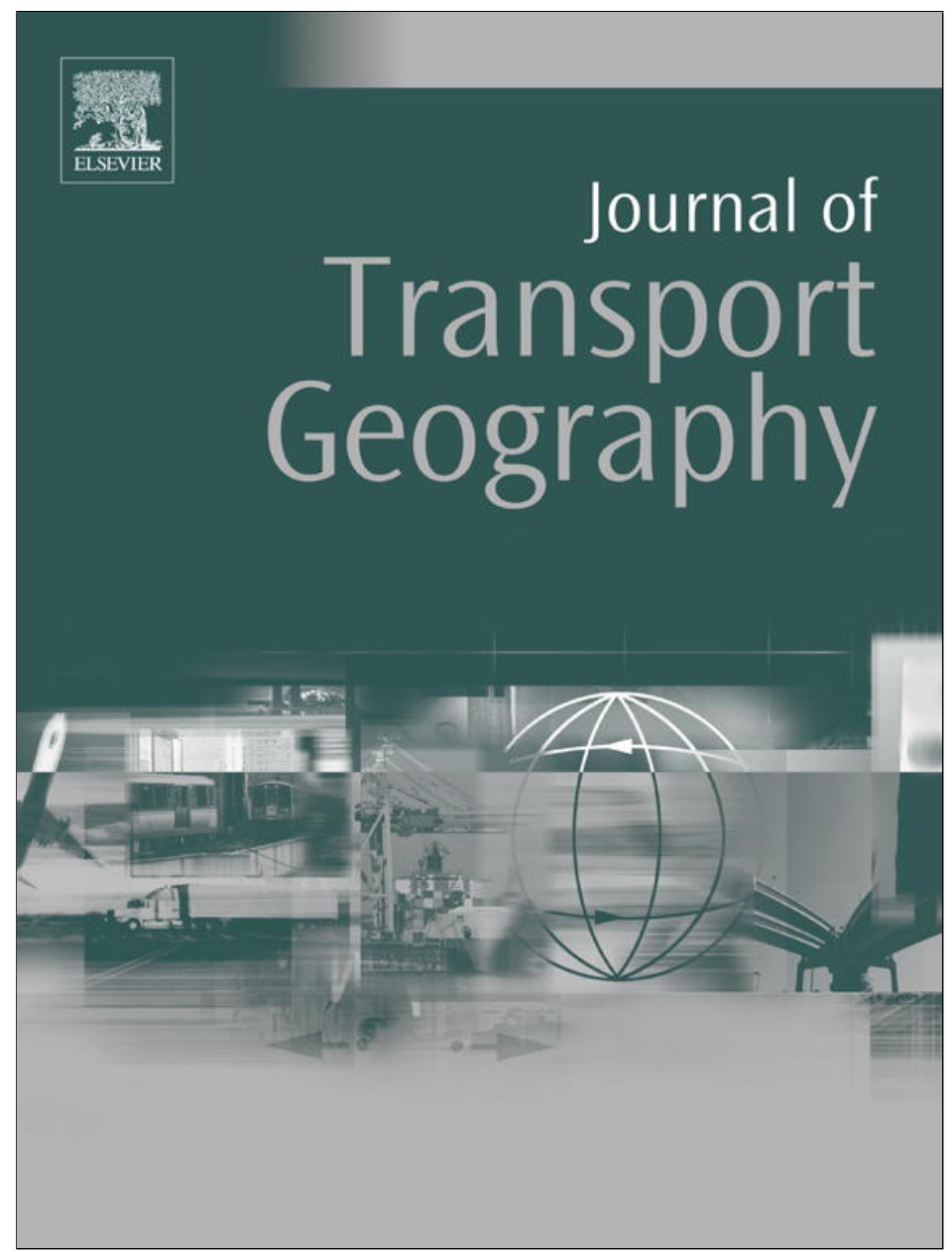

(This is a sample cover image for this issue. The actual cover is not yet available at this time.)

This article appeared in a journal published by Elsevier. The attached copy is furnished to the author for internal non-commercial research and education use, including for instruction at the authors institution and sharing with colleagues.

Other uses, including reproduction and distribution, or selling or licensing copies, or posting to personal, institutional or third party websites are prohibited.

In most cases authors are permitted to post their version of the article (e.g. in Word or Tex form) to their personal website or institutional repository. Authors requiring further information regarding Elsevier's archiving and manuscript policies are encouraged to visit:

http://www.elsevier.com/copyright 


\title{
School commuting: the relationship between energy consumption and urban form
}

\author{
Anne-Francoise Marique ${ }^{\mathrm{a}, *}$, Sébastien Dujardin ${ }^{\mathrm{b}}$, Jacques Teller $^{\mathrm{a}}$, Sigrid Reiter ${ }^{\mathrm{a}}$ \\ ${ }^{a}$ Local Environment: Management $\mathcal{E}$ Analysis, LEMA, University of Liège, Belgium \\ ${ }^{\mathrm{b}}$ Research Centre on Territorial, Urban and Rural Sciences, Lepur, University of Liège, Belgium
}

\section{A R T I C L E I N F O}

\section{Keywords:}

School commuting

Transport energy consumption

Urban structure

Mode choice

Belgium

\begin{abstract}
A B S T R A C T
A large amount of research in the past has focused on the relationships between the energy consumption for home-to-work travel and land-use patterns. However, little is known about children's mobility. This paper analyses the energy consumption, travel distances and mode choices for school commuting based on two decennial surveys in Belgium. The results highlight the following: (1) mobility behaviours have evolved drastically over the past decades for school commuting, an evolution that cannot be entirely related to land-use variables, (2) the energy consumption for school commuting is strongly dependent upon the school level, and (3) the links between land-use patterns and energy consumption for school commuting are different than those highlighted within the literature between urban forms and hometo-work commutes. The concentration of secondary schools and tertiary institutions in urban centres induces higher energy consumption rates, whereas the decentralisation of nursery and primary schools across the entire territory leads to very low local energy consumption and increased walking and cycling. These results provide a better understanding of school commuting within the European context and could guide future policies focused on transport energy consumption at the local scale.
\end{abstract}

(c) 2012 Elsevier Ltd. All rights reserved.

\section{Introduction}

Transport is a major contributor to the increasing level of energy consumption and greenhouse gas emissions worldwide. In the European Union, the transport sector accounted for $31 \%$ of the total final energy consumption in 2005, up from 26\% in 1990 (European Commission, 2008). Levels of mobility also continue to rise substantially, and the transport energy demand in 2030 is projected to be $28 \%$ higher than in 2005 (European Commission, 2008). Given the levels and growth of energy use in the transport sector, there is an urgent need for measures to control the growth of and reduce the dependence on motorised vehicles and imported oil. Thus, much research has focused on the links between transport energy consumption (particularly in home-to-work commuting) and the urban structure of a region. Energy consumption related to transport is an interesting indicator because it is a composite measure of travel distance, transport mode choice and journey frequency (Banister, 1998; Muniz and Galindo, 2005).

One of the first and most influential studies on this relationship was conducted by Newman and Kenworthy (1989, 1999). They

\footnotetext{
* Corresponding author. Address: Local Environment: Management \& Analysis, LEMA, University of Liège, Chemin des Chevreuils, 1 B52/3, B - 4000 Liege, Belgium. Tel.: +32 436693 67; fax: +32 43662909 .

E-mail address: afmarique@ulg.ac.be (A.-F. Marique).
}

highlighted a strong inverse relationship between urban density and transport consumption based on data from 32 large, international cities. However, their work is valid only for certain conditions and has often been criticised by other researchers (Gordon and Richardson, 1989; Mindali et al., 2004), mainly for methodological reasons. Banister (1992) used the same kind of approach with British cities, but his study was based on statistical data obtained from a national survey. He demonstrated that transport energy consumption is slightly higher in London than in smaller cities, which contradicts Newman and Kenworthy's observations. Boarnet and Crane (2001) also are sceptical about the relationship between urban design and transport behaviours. After analysing case studies, they suggested that land use and urban form influence transport behaviours because of the price of travel (public transport prices are lower in dense areas). Gordon and Richardson (1997) demonstrated that urban density plays only a limited role in transport energy consumption if fuel prices are included in the analysis. Breheny (1995) emphasised that only minor reductions in transport energy consumption are associated with the compact-city model. His experiments showed that the energy used in transport could only be reduced by $10-15 \%$, even under very strict conditions that are difficult to reproduce.

However, Ewing and Cervero (2010) highlighted the finding that per capita vehicle travel tends to decline, and the use of alternative modes increases, with a rise in density. For these authors, compact developments, which reflect the cumulative effects of 
increased density, functional mix and transit accessibility, typically reduce per capita vehicle travel by $25-30 \%$. In the same vein, Stead (2001) found that $43 \%$ of the variation in travel distances was explained by socio-economic variables, but $27 \%$ of the variation a considerable amount - was directly related to land-use variables.

As presented above, a growing body of literature supports the notion that urban form plays a role in travel mode choice and transport energy consumption for adults. However, relatively little is known about how urban form influences children's travel and energy consumption for school commuting, and hence the empirical findings on children's school travel outcomes are less conclusive (McMillan, 2005; Mitra and Buliung, 2012). Therefore, this paper studies the links between land-use patterns, children's trips to and from school and energy consumption for school commuting. A focus on school commuting allows for comparisons with commuting to work. Moreover, promoting ways to reduce energy consumption for school commuting will have positive returns for both the environment and individual health.

Section 2 presents a review of the literature on children's mobility and urban form. Section 3 describes the context of the study (the Walloon region of Belgium), the data set and the quantitative method used to assess transport energy consumption. Section 4 discusses the evolution of travel distances and mode choices for school commuting. In Section 5, the energy consumption for school commuting is calculated, discussed and compared with home-towork energy consumption. A distinction is made between primary, secondary and tertiary education. Section 6 presents the reproducibility and opportunities of the approach developed in the paper. and the main findings are summarised in Section 7.

\section{School commuting}

Since the first works by Hillman et al. (1990), research on child and youth mobility has largely focused on the declining use of active commuting (cycling and walking) and children's independent mobility (the opportunity for children to move freely in the environment without an accompanying adult) in the West, as well as the increasing prevalence of physical inactivity and obesity among children and youth (Buliung et al., 2012; Gilbert and O'Brien, 2005). Research studies have examined correlations between personal, family, social and environmental factors and children's active/independent commuting to and from school, mainly focusing on health and obesity. The main conclusions of these studies are that the likelihood of walking or cycling to school decreases as travel distance increases, but it is also correlated with the safety of routes and family time constraints (Dellinger and Staunton, 2002; Ewing et al., 2004; Faulkner et al., 2010; McDonald and Aalborg, 2009; McMillan, 2006; Mitra et al., 2010; Sjolie and Thuen, 2002; Timperio et al., 2006; Trapp et al., 2011; Yeung et al., 2008; Ziviani et al., 2004). Previous research has also identified parents' concerns about the absence of adult supervision, the age of the child and fears related to children being assaulted by strangers as primary barriers to active commuting to school. In this respect, gender affects school travel. Boys seem to be more likely to walk and especially to cycle to school (McDonald, 2012; McMillan et al., 2006). An emerging research topic not only concerns the qualitative work on parents' perceptions but also addresses children's perceptions of school travel and the built environment (Faulkner et al., 2010; Fusco et al., 2012; Line et al., 2010). Children are now considered "active agents" who are able to express their own needs about school travel (Fusco et al., 2012). Finally, recent studies have highlighted the importance of taking into account both social and environmental issues (Feng et al., 2010; Gilbert and O'Brien, 2005; McMillan 2005, 2006; Saelens and Handy, 2008) and they have attempted (in this regard) to indicate how cities can be changed to improve children's independent mobility. These strategies can be grouped into three broad categories: changing urban form and transport, changing the design of local neighbourhoods and changing social values (Tranter and Sharpe, 2012).

There is no consensus on the definitions of child and youth in research on child mobility. Buliung et al. (2012), following Holloway and Valentine (2000), argued that "these definitions may be differentially constructed across time and place" (p. 31). Nayak (2003) made the same observation in the broader field of geography and children's perception of crime. For statistical purposes, several institutions (World Bank, UNICEF, etc.), as well as the special section on child and youth mobility of the Journal of Transport Geography (Buliung et al., 2012), have adopted the United Nations (2011) definition of "youth" as those persons between the ages of 15 and 24 and "children" as those persons 14 years old or younger. Hillman et al. (1990) distinguished between junior school children (aged 7-11) and senior school children (aged 11-15). In this paper, "child" and "youth" are defined by school level rather than age.

Although exceptions exist (e.g., Hillman et al. (1990) in England, Sjolie and Thuen (2002) in Norway and Susilo and Waygood (2012) in Japan), most research on children's mobility has been conducted in North America, which raises questions about the generalisability of these findings to other regions, as highlighted by Cervero et al. (2009) in the case of Bogota (Colombia). Relatively little is known about children's mobility in Europe, although European regions and built environments have several significant differences from the countries discussed above.

\section{Study area and methods}

\subsection{Study area: the Walloon region of Belgium}

This paper focuses on the Walloon region of Belgium (Fig. 13.5 million inhabitants), which is located in the southern, Frenchspeaking part of the country. The region covers a total area of 16,843 square kilometres. The Brussels capital region (which has more than one million inhabitants, the largest agglomeration in the country) is centrally located in Flanders (Boussauw and Witlox, 2011), but it has a strong relationship with the Walloon region. The two main urban areas in the Walloon region are Liège $(600,000$ inhabitants) and Charleroi (400,000 inhabitants). Other regional cities (from west to east: Tournai, Mons, Namur, Huy, and Verviers) are located along the former industrial basin. The rest of the region is composed of a series of smaller urban centres and municipalities, as well as numerous suburban settlements. Suburban Walloon settlements are spread throughout the region, not only near dense urban centres or rural cores, because of the availability of important land resources (low land pressure) and easy access to railway and road networks. This configuration, and the relative infrequency of public buses outside the main cities, makes these settlements highly car-dependent.

\subsection{Education system and admissions policies}

In Belgium (Table 1), education is compulsory and free for students from 6 to 18 years of age. Nursery school is intended for children from 3 to 6 years old, but it is not compulsory. Primary school consists of the first 6 years of formal, structured education, starting at the age of 5 or 6 . After successfully completing a final exam, students attend a secondary school for six additional years of general, technical or professional education. This level of schooling provides final access to tertiary education. There are no admissions policies that require children to attend one school rather than another for nursery and primary schools in Belgium. For tertiary 


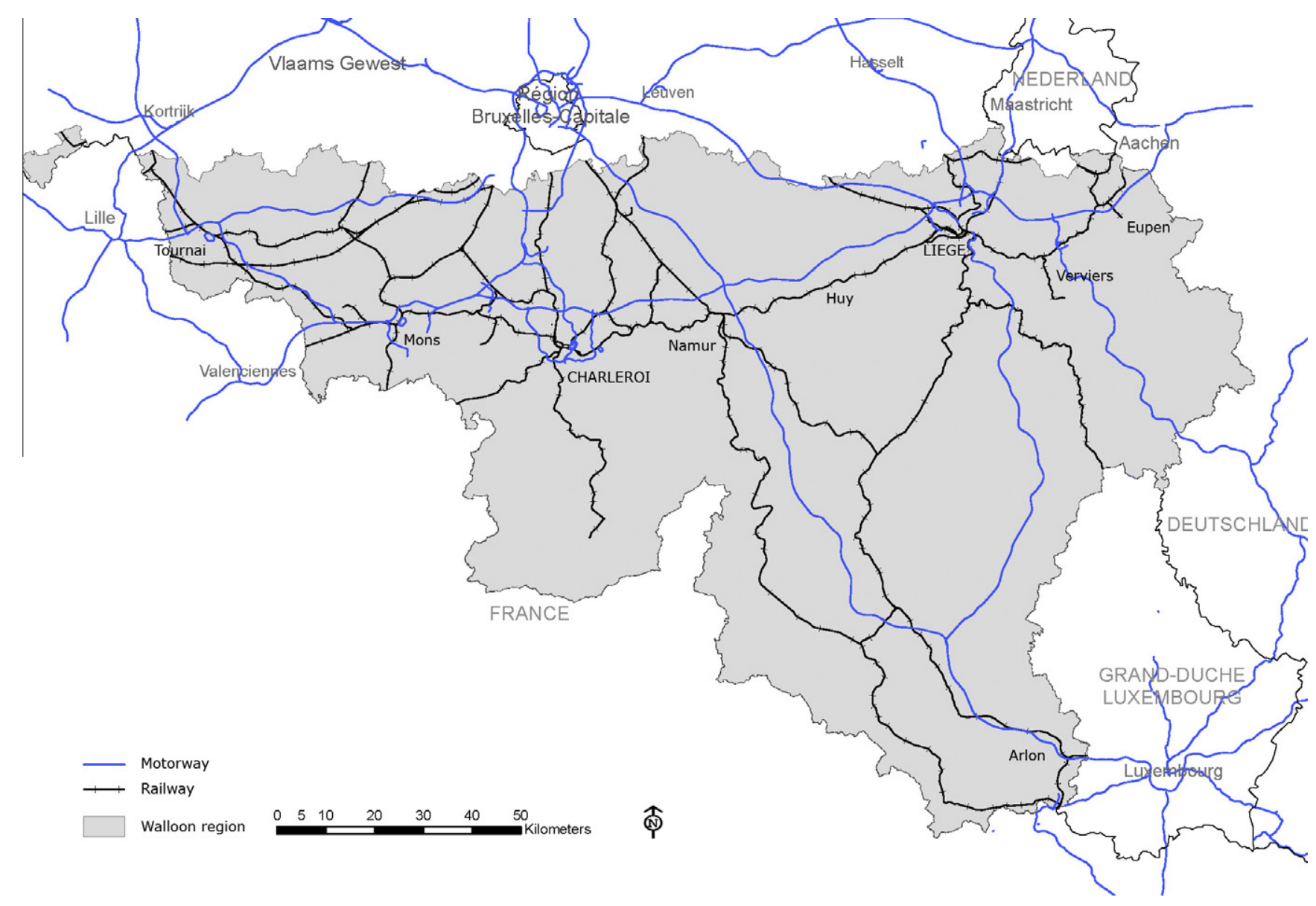

Fig. 1. The study area.

Table 1

Summary of school levels in the Walloon region (Belgium).

\begin{tabular}{llll}
\hline School level & Age of the pupils & Attendance requirements & Admissions policy \\
\hline Nursery school & $3-6$ years old & Optional & None \\
Primary school & $6-12$ years old & Compulsory & None \\
Secondary school & $12-18$ years old & Compulsory up to 18 years old & Completion of the primary school final exam \\
Tertiary education & More than 18 years old & Optional & Completion of the secondary school final exam \\
\hline
\end{tabular}

education, the only criterion is the completion of the secondary school final exam. For secondary schools, a decree was adopted in 2010 for the French-speaking part of the country, the aim of which was to promote social diversity, fairness and transparency in assignment to secondary schools. Secondary school assignment is determined by a formula that takes into account the distance between the residence and the school as well as socio-economic factors.

\subsection{Methods and data sets}

The quantitative method used to evaluate transport energy consumption in school commuting in Section 5 is based upon work by Boussauw and Witlox (2009) and Marique and Reiter (2012) on home-to-work commutes. Boussauw and Witlox (2009) developed a commute-energy performance index and tested it for Flanders and the Brussels capital region in Belgium. Their aim was to investigate the link between spatial structure and energy consumption for home-to-work travel at the municipal scale. Using the same kind of methodology, Marique and Reiter $(2011,2012)$ and Dujardin et al. (2012) investigated links between home-to-work commuting and the spatial structure of the Walloon region of Belgium. These local-scale approaches not only showed that the main cities have low energy consumption, but also highlighted the existence of secondary urban cores with low transport energy consumption. These studies found that the relocation of residences and jobs to suburban areas leads to more energy for home-to-work commuting in some urban regions but less in others. Thus, these papers showed that the distance between home and destination is paramount, whereas the mode of transport has a lesser impact.

For the present study, a school-commute energy performance index is defined and expressed in $\mathrm{kW}$ h/travel student, which represents the mean energy consumption for home-to-school travel for one student living in a former municipality (this is an administrative boundary; see Fig. 2). This index takes into account the travel distances, the means of transport used and their relative consumption rates, expressed by Eq. (1). In this equation, $i$ represents the former municipality; $m$ is the means of transport used (diesel car, fuel car, train, bus, and bicycle or on foot); Dmi is the total distance travelled by means of transport $m$ in district $i$ for 


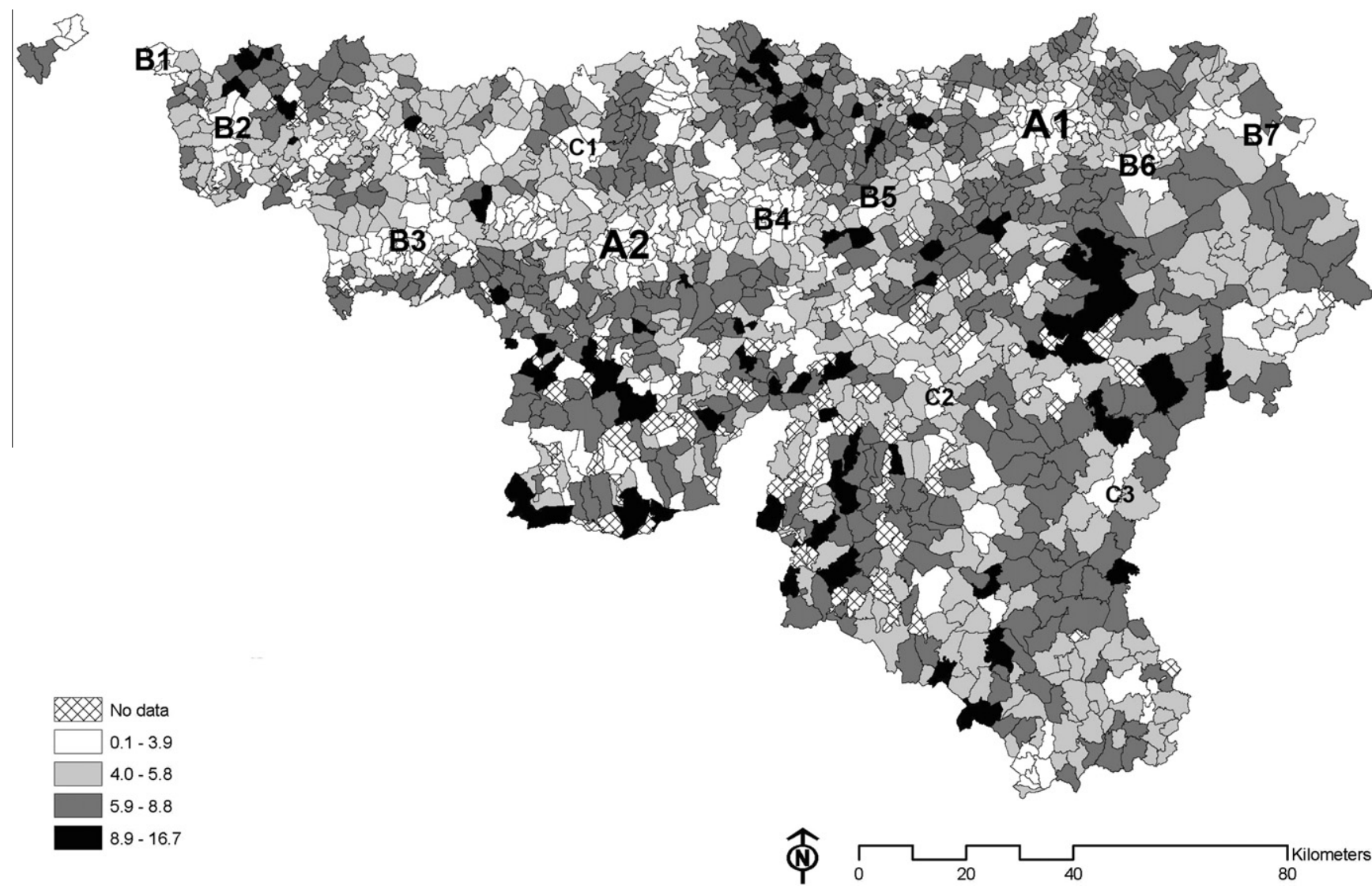

Fig. 2. Energy consumption (kW h/travel student) for school commuting (all levels included), at the former-municipal scale.

home-to-work (or home-to-school) travel; $f m$ is the consumption factor attributed to each means of transport $m$; and $T i$ is the number of workers (or students) in the territorial unit $i$.

School-commute energy performance index $(i)$

$$
=(\Sigma m D m i * f m) / T i
$$

The consumption factors $\mathrm{fm}$ were calculated for the Walloon region of Belgium based on regional and local data, and they take into account mean fuel consumption of the vehicles (litres per kilometre), the passenger rate and the characteristics of the fuel. For trains, the consumption factor used depends on the production of electricity, as most trains in Belgium are electric. The consumption factors are $0.56 \mathrm{~kW} \mathrm{~h} /$ person $\mathrm{km}$ for a diesel car, $0.60 \mathrm{~kW} \mathrm{~h} /$ person $\mathrm{km}$ for a fuel car, $0.45 \mathrm{~kW} \mathrm{~h} /$ person $\mathrm{km}$ for a bus, $0.15 \mathrm{~kW} \mathrm{~h} /$ person $\mathrm{km}$ for a train and 0 for non-motorised means of transport, as these do not consume any energy.

The travel distances and travel mode data were gathered from the national censuses, which are conducted in Belgium every 10 years. The 1991 and 2011 censuses were used. Information was available about car ownership, travel distances and the primary mode of transport used, as well as demographic and socioeconomic data, for the Belgian population older than 6 years. The general response rate for the 2001 survey was $95 \%$, with some variations depending on the sections of the questionnaire. Only students who answered all questions dealing with school commuting and education were included. If a journey was made by two (or more) modes of transport, only the primary mode was used. This was determined by the speed of travel of each mode, because the fastest travel mode is usually the one used for the longest distance. Thus, the primary travel mode was determined according to the following hierarchy: train, car, bus and bicycle/on foot. For students in tertiary education who rented flats closer to their school than their parents' house was, the flat was considered the main residence. Individual data were aggregated at the census-block (or district) scale, the former-municipal (intermediate) scale and the municipal scale. Note that there are 9730 census blocks, 1472 former municipalities and 262 municipalities in the Walloon region. To increase statistical reliability, census blocks with fewer than 10 respondents were omitted. The final sample was composed of 183,617 (25.0\%) of the 734,000 students (all levels included) attending school in the Walloon region. Results are reported at the former-municipal level, as data at this level are more easily handled than those at the census-block scale but still make it possible to highlight local phenomena that would be missed at the municipal scale.

\section{Travel distances and mode choice}

The mean travel distance differs with the level of schooling: the average distance between home and school is $5.4 \mathrm{~km}$ for nursery and primary schools, $10.7 \mathrm{~km}$ for secondary schools and $21.2 \mathrm{~km}$ for tertiary institutions. By comparison, the mean travel distance for home-to-work travel was $24.0 \mathrm{~km}$ in the Walloon region of Belgium in 2001. Although the mean travel distances from home to work and to tertiary institutions are fairly similar, the travel mode choices are quite different.

Tables 2 and 3 summarise the travel mode choices for school commuting and travel distances according to level of education. Mode choices and travel distances for work commuting are given to facilitate comparisons. Sixty-six percent of trips from home to nursery and primary schools are less than $5 \mathrm{~km}$. The school catchment area for nursery and primary schools is generally 
Table 2

Travel mode choice for school commuting by level of education, and for work commuting.

\begin{tabular}{|c|c|c|c|c|c|c|}
\hline & On foot (\%) & Bicycle (\%) & Motorbike (\%) & Car $(\%)$ & Bus (\%) & Train (\%) \\
\hline Nursery and primary schools & 21.3 & 2.4 & 0.0 & 67.0 & 9.0 & 0.3 \\
\hline Secondary schools & 12.0 & 1.3 & 1.7 & 37.0 & 41.2 & 6.8 \\
\hline Tertiary institutions & 12.8 & 0.8 & 0.7 & 33.3 & 36.2 & 16.2 \\
\hline Work commute & 5.4 & 1.2 & 1.9 & 80.2 & 4.1 & 7.2 \\
\hline
\end{tabular}

Table 3

Travel distances for school commuting by level of education, and for work commuting.

\begin{tabular}{|c|c|c|c|c|}
\hline & $0-5 \mathrm{~km}(\%)$ & $5-20 \mathrm{~km}(\%)$ & $20-50 \mathrm{~km} \mathrm{( \% )}$ & $>50 \mathrm{~km}(\%)$ \\
\hline Nursery and primary schools & 66.6 & 28.6 & 4.1 & 0.8 \\
\hline Secondary schools & 31.1 & 54.5 & 12.6 & 1.8 \\
\hline Tertiary institutions & 19.5 & 35.7 & 35.7 & 9.1 \\
\hline Work commute & 25.7 & 37.1 & 24.8 & 12.5 \\
\hline
\end{tabular}

the size of the municipality, which supports active commuting (walking and cycling) for a large proportion of the students (23.7\%) relative to secondary schools (13.3\%) and tertiary institutions (13.6\%). Nevertheless, the private car is the preferred mode of transport from home to nursery and primary schools (67.0\%), whereas the use of public transport is low (9.0\% for buses and $0.3 \%$ for trains). The growing size of secondary schools and tertiary educational institutions and their smaller number increase the average travel distances and reduce the likelihood of walking. As the number of short trips (less than $5 \mathrm{~km}$ ) decreases, private car use also decreases significantly compared with public transport. Private car use is significantly lower for school commuting than it is for work commuting. Trips by bus represent $41.2 \%$ and $36.2 \%$ of all trips to secondary schools and tertiary institutions, respectively. The train seems to be a credible alternative only for tertiary institutions (16.2\%) because of the longer commuting distances (44.8\% of trips are greater than $20 \mathrm{~km}$ ). Active commuting is only used for a significant proportion of trips when distances are very short. Walking and cycling represented $63.7 \%$ of all trips to school of less than $1 \mathrm{~km}$ in 2001 , (54.5\% for primary schools, $76.2 \%$ for secondary schools and $91.5 \%$ for tertiary institutions). Active commuting represented only $4.9 \%$ of trips longer than $5 \mathrm{~km}$ (2.5\% for primary schools, $6.5 \%$ for secondary schools and $7.5 \%$ for tertiary institutions). The travel mode choice and travel distance are clearly correlated, confirming that the distance to school is one of the key factors in determining children's mode of transport to school, as most studies on school travel have shown.

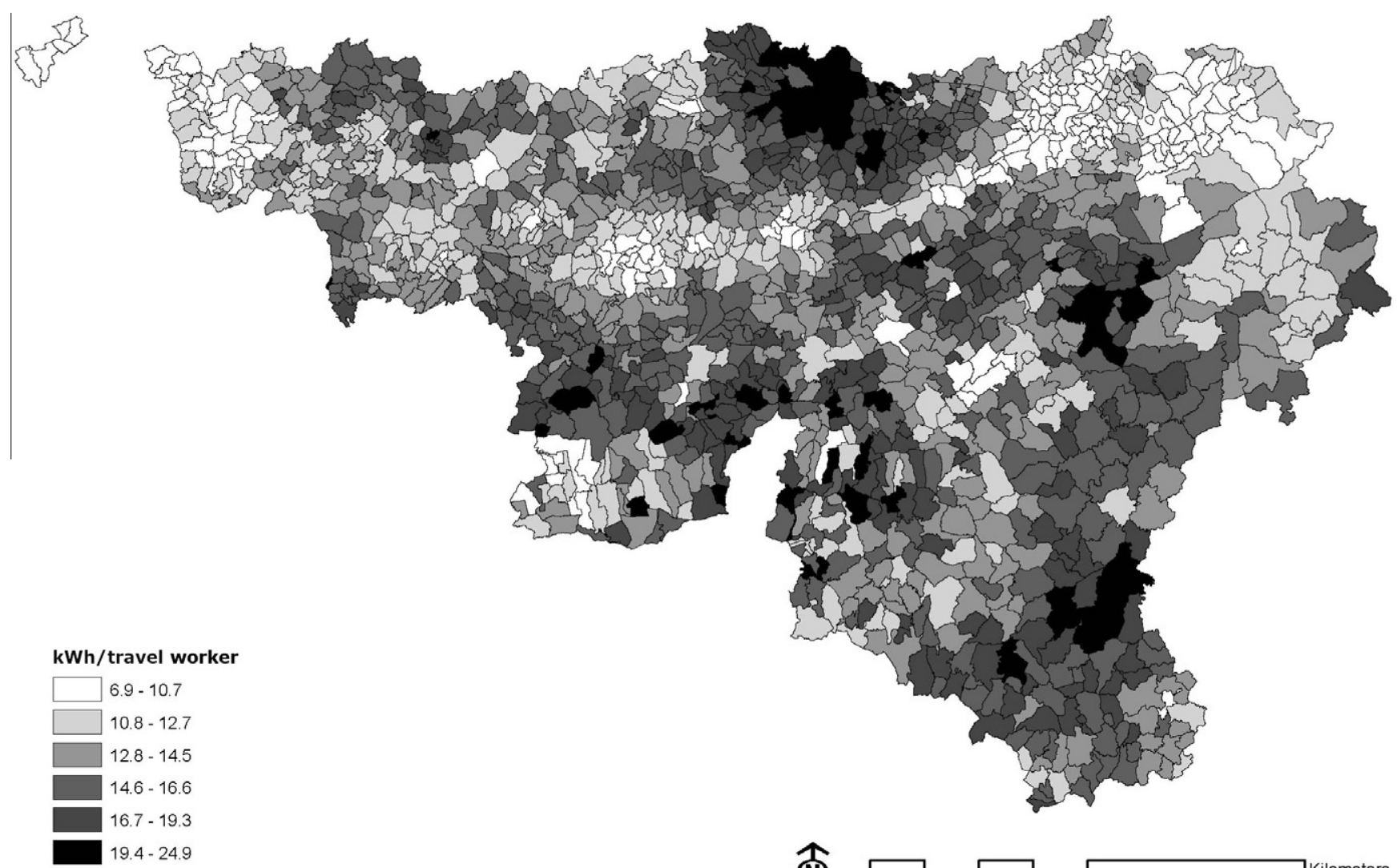

Classification: Natural breaks

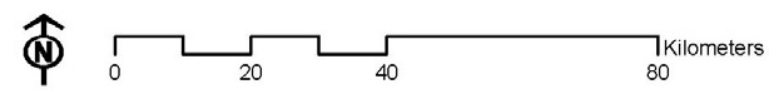

Fig. 3. Energy consumption (kW h/travel worker) for home-to-work commuting (Marique and Reiter, 2011), at the former-municipal scale. 


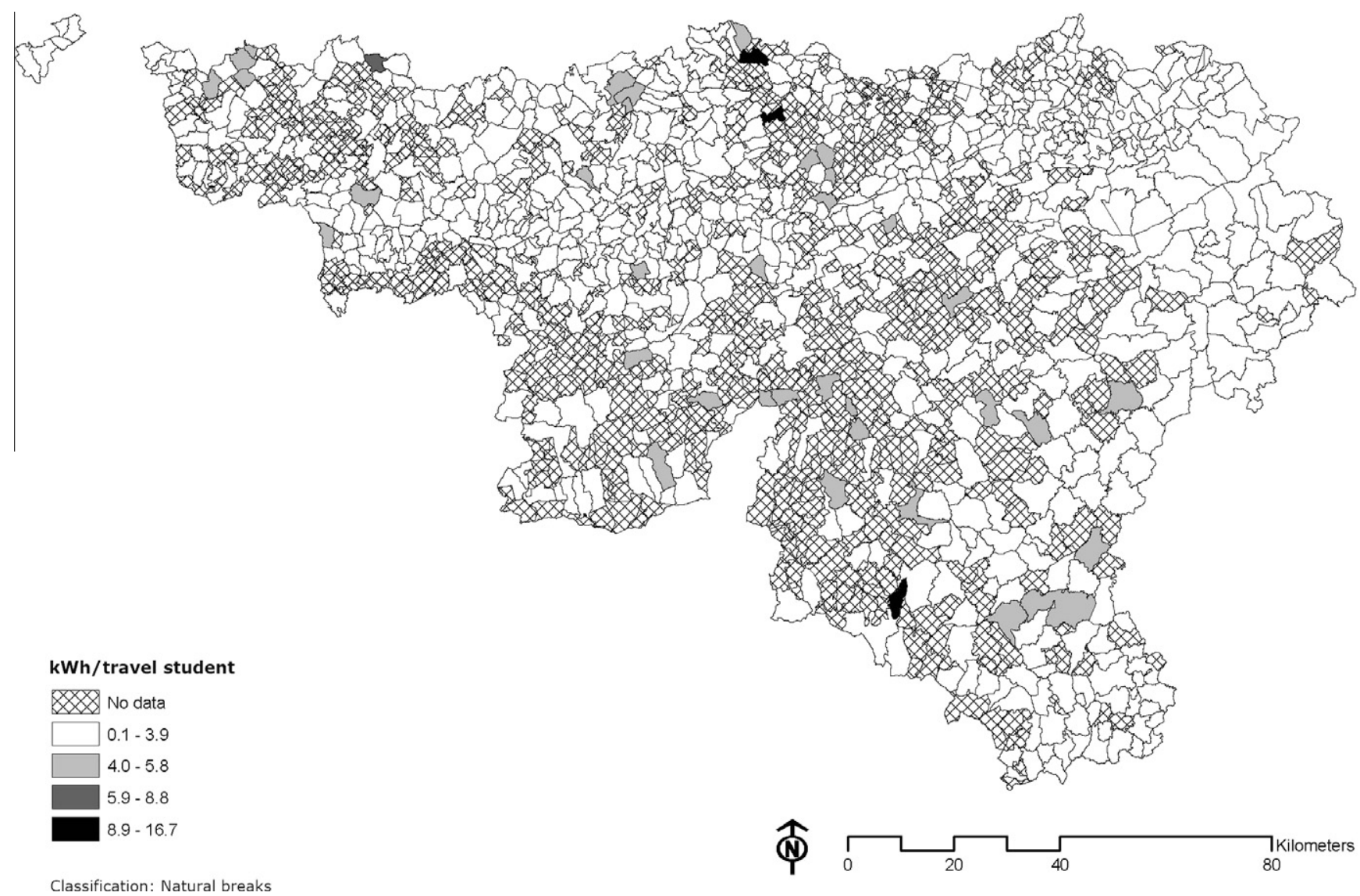

Fig. 4. Energy consumption (kW h/travel student) for school commuting (nursery and primary schools), at the former-municipal scale.

A comparative analysis of the data from the 1991 and 2001 national censuses also shows important changes in the mode choice for school commuting over time. In 1991, walking and cycling represented $28.9 \%$ of all trips to school, whereas private car use accounted for $38.1 \%$. In 2001, active commuting represented only $17.0 \%$ of journeys to school, whereas car use had risen to $46.8 \%$. Train commuting dropped from $6.4 \%$ in 1991 to $6.1 \%$ in 2001 , whereas bus trips rose from $26.5 \%$ to $29.1 \%$ during the same period. This shift in travel modes is not specific to the Walloon region of Belgium. Similar changes have been observed in other countries. In the United States, walking and cycling to school declined from 48\% in 1969 to 13\% in 2009 (McDonald et al., 2011; McDonald, 2012). Walking and cycling represented $87 \%$ of all trips to school of less than one mile $(1.609 \mathrm{~km})$ in 1969 , whereas car use accounted for only $7 \%$ of trips (McMillan, 2006). By 2001, 36\% of trips to school less than one mile $(1.609 \mathrm{~km})$ were made by car, whereas the percentage of active commuting (walking and cycling) had dropped to 55\% (McDonald, 2005). In England, walking to school by primary-aged children dropped from 61\% in 1992/1994 to $52 \%$ in $2002 / 2003$, whereas car use increased from $30 \%$ to $40 \%$ (Department for Transport, 2005). The same trend was also observed in Australia, where the decline in children's active transport to school is particularly marked. The percentage of children walking to school decreased from $58 \%$ in 1971 to $26 \%$ in 2003 , whereas car use increased from 12\% to 48\% (Tranter and Sharpe, 2012; Van der Ploeg et al., 2008). In the Greater Toronto Area (Canada), walking to school declined for both 11-13-year-old (53-42.5\%) and 1415-year-old (38.6-30.7\%) students (Buliung et al., 2009). As the figures used in the present study show, active commuting to school remains low in the Walloon region of Belgium. This trend can be partly explained by the strong decentralisation of residential areas associated with continuous urban sprawl in the Walloon region, which tends to significantly increase distances between home and school.

\section{Energy consumption for school commuting}

The school-commute energy performance index, presented in Section 3.3, was calculated and mapped for the Walloon region of Belgium at the former-municipal scale. All students from nursery school to tertiary education are included in Fig. 2. The two main cities, Liège and Charleroi ( $\mathrm{A} 1$ and $\mathrm{A} 2$ in Fig. 2), had the lowest energy consumption rates. Several towns and neighbourhoods located along the former industrial basin (from west to east: Mouscron (B1), Tournai (B2), Mons (B3), Charleroi, Namur (B4), Huy (B5), Liège, Verviers (B6) and Eupen (B7)) also had low energy consumption rates for school commuting. A high-density built environment, with mixed land use and good public transport, seems to favour low transport energy consumption for school commuting. There are two main differences between these energy consumption results and those for home-to-work commuting (Fig. 3). First, home-to-school journeys consume much less energy per capita and per trip than home-to-work journeys, mainly because of the shorter distances and the greater use of public transport (bus and train). The mean regional energy consumption is $4.1 \mathrm{~kW} \mathrm{~h} /$ travel student for school commuting, compared with $12.1 \mathrm{~kW}$ h/travel worker for work commuting. Second, the relationships between the spatial structure of the territory and the energy consumption for school commuting are difficult to characterise, but these relationships are more obvious for home-to-work travel (Fig. 3). Marique and Reiter (2011) and Dujardin et al. (2012) 


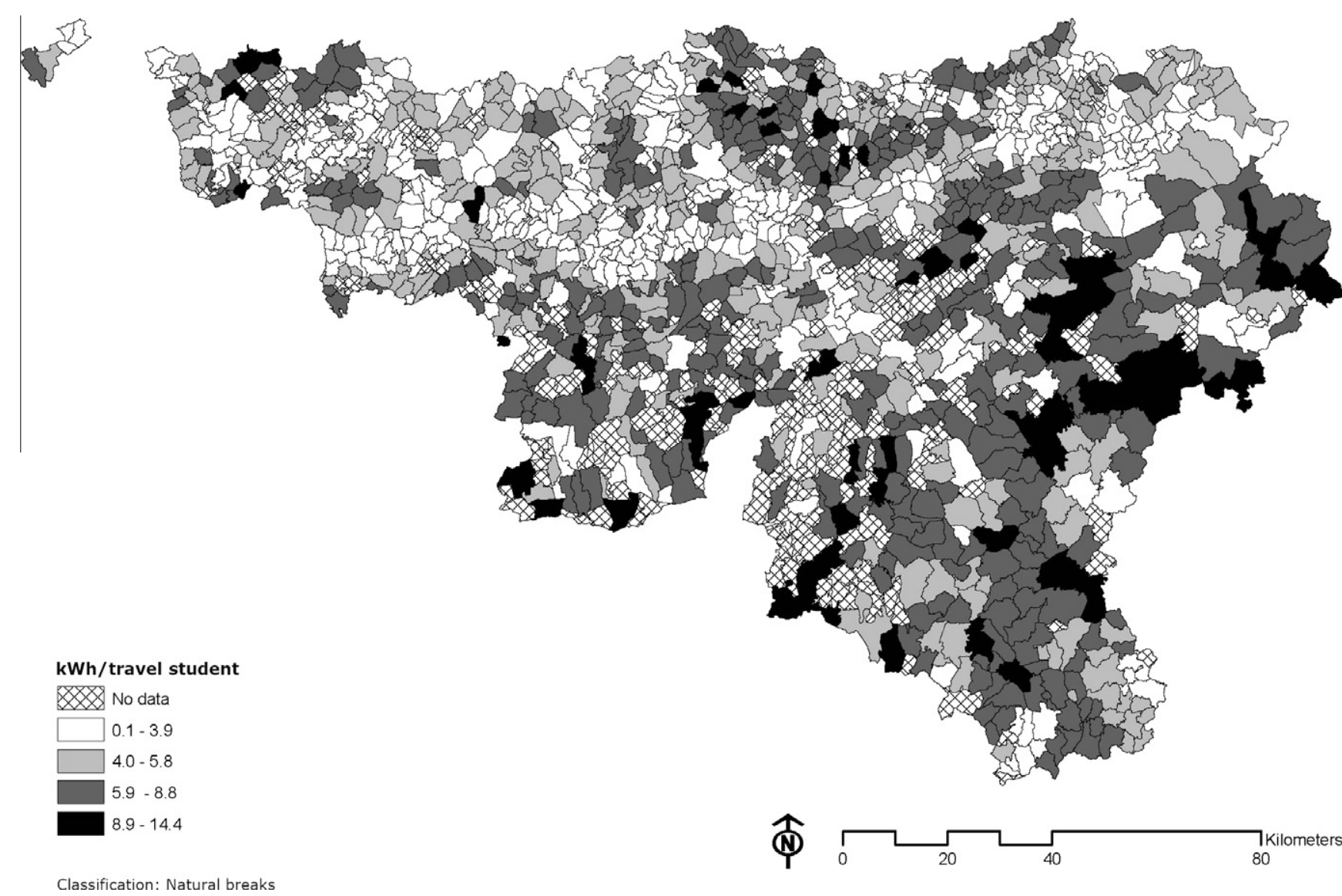

Fig. 5. Energy consumption (kW h/travel student) for school commuting (secondary schools), at the former-municipal scale.

found that the main cities of the region were among the most energy-efficient areas (in white and light grey in Fig. 3) for home-towork energy consumption, along with many other entities in less densely populated areas outside the influence of the main cities but with a good mix of employment options and population. Suburban settlements, mainly those located in the metropolitan areas of Brussels and Luxembourg, are among the less energy-efficient areas (in black in Fig. 3). These areas combine poor accessibility to public transport and long commuting distances to employment centres.

Energy consumption for commuting to nursery and primary schools (Fig. 4), secondary schools (Fig. 5) and tertiary institutions (Fig. 6) was examined separately to refine these observations. The higher the school level, the higher the energy consumption for school commuting. The mean energy consumption for school commuting to primary, secondary and tertiary institutions was $1.1,3.7$ and $6.8 \mathrm{~kW} \mathrm{h/travel} \mathrm{student,} \mathrm{respectively.} \mathrm{The} \mathrm{energy} \mathrm{consumption}$ per capita for commuting to primary school is low across the entire territory based on the spatial distribution of the school-commute energy performance index. The concentration of education infrastructure in secondary towns and main cities (especially secondary schools and tertiary institutions) highlights the greater peripheral distribution of the performance index for school commuting. Such patterns for the school-commute energy performance index are common for secondary schools and are quite similar to the ones seen for home-to-work commuting. Areas with the lowest energy consumption rate correspond to the main municipalities located along the former industrial basin, as well as to small urban centres outside the influence of the main cities, such as Nivelles, Marche and Bastogne (C1, C2 and $\mathrm{C} 3$ in Fig. 2). The concentric spatial pattern is more pronounced in the case of tertiary education, which is especially apparent around the urban areas of Liège, Louvain-laNeuve and Mons. These education hubs attract a large number of students from the suburbs and from further afield because of their regional importance in tertiary education. The high energy performance index in the German-speaking part of the region (East) shows the absence of tertiary institutions in this area. Nonetheless, it has a very low energy consumption rate for home-to-work commuting and for travel to primary and secondary schools.

Differences in the spatial pattern of the performance index for school commuting at different education levels can be explained by the geographical distribution of the types of school in the region. The ratio between the capacity of a municipality to provide education (e.g., the number of places in schools) and the number of students living in the municipality was calculated. Fig. 7 presents this "educational capacity-to-demand" ratio for former municipalities with a ratio greater than 1 , for the three levels of schooling considered.

Fig. 8 shows that the number of students living in a given municipality is always very close to the number of places in nursery and primary schools in that municipality, which means that the mobility of nursery and primary school pupils is limited. Nursery and primary schools are found throughout the region (only 39 of the 262 municipalities do not have any nursery or primary schools) and serve local children living in the municipality. Seventy-five municipalities have an educational capacity-to-demand ratio greater than 1 . By contrast, many of the municipalities do not have a secondary school, especially in the southern, less densely populated part of the region. Only 47 municipalities have an educational capacity-to-demand ratio greater than 1 for secondary education. Very few municipalities provide tertiary education. Therefore, tertiary institutions attract students from across the region, which 

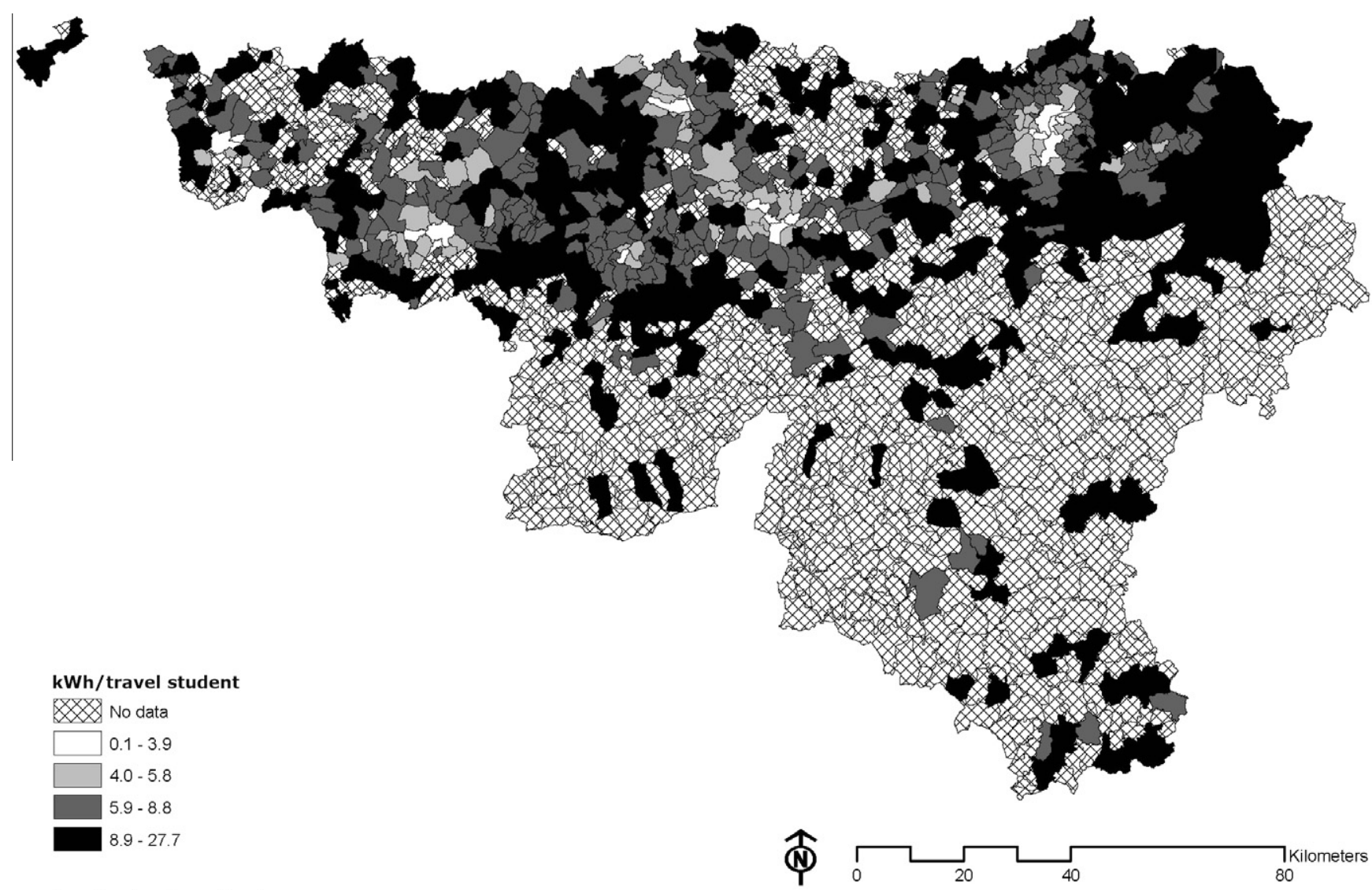

Fig. 6. Energy consumption (kW h/travel student) for school commuting (tertiary institutions), at the former-municipal scale.
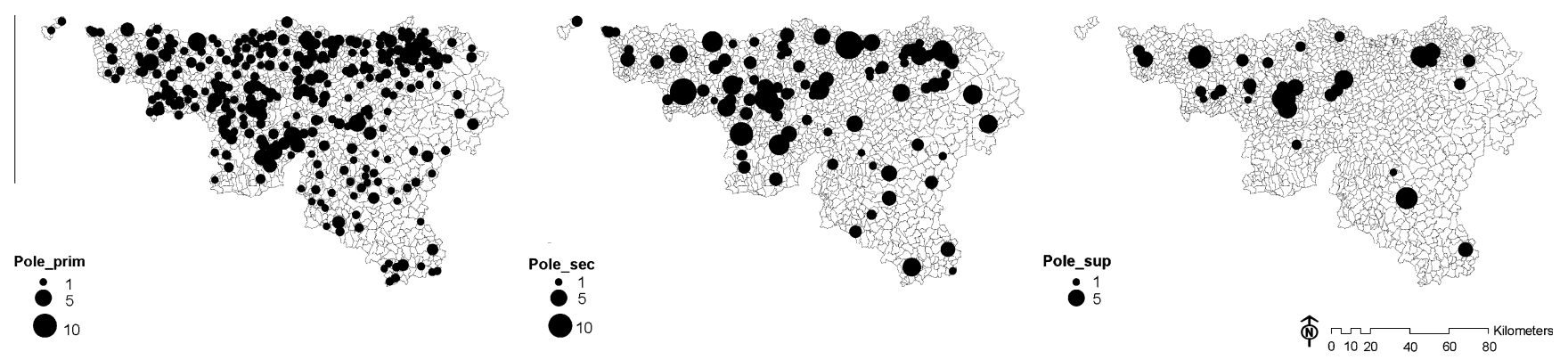

Fig. 7. Former municipalities with an educational capacity-to-demand ratio greater than 1 , for primary schools (left), secondary schools (middle) and tertiary institutions (right).

means longer commuting distances. Only 15 municipalities have an educational capacity-to-demand ratio greater than 1 for tertiary education.

As far as explanatory variables are concerned, the maps of the travel distances between home and school are remarkably similar to the energy consumption maps. These parameters are strongly correlated $\left(r^{2}=0.83\right)$, which highlights the fact that the travel distance is of primary importance in the energy performance of school commuting. Studies of home-to-work travel (Boussauw and Witlox, 2009; Marique and Reiter, 2012) have found that the mode of transport for home-to-work travel has little impact because of the relationship between the consumption factor and the mean travel distance per mode of transport. For example, the consumption factor used for train travel is approximately four times lower than the consumption factor for private cars, but trips by train are much longer than trips by car, which reduces the impact of the train's lower consumption factor. This relationship is not valid for school commuting, because shorter distances can also be covered by bus and train.

Finally, multivariate regression analyses were performed to clarify some of the mechanisms underlying the relationship between the urban structure of the region and commuting. Four local characteristics were used in the model to explain the school-commute energy performance index: population density, the modal share of active commuting (the share of students in the municipality commuting by foot or bicycle), school accessibility (the number of places in schools within $5 \mathrm{~km}$ of the place of residence) and household income. Variables were subjected to a logarithmic transformation, as they were normally distributed. A significant effect of the selected variables on the energy performance index for school commuting was found for secondary schools and for tertiary institutions (Table 4). The share of active commuting explained the 

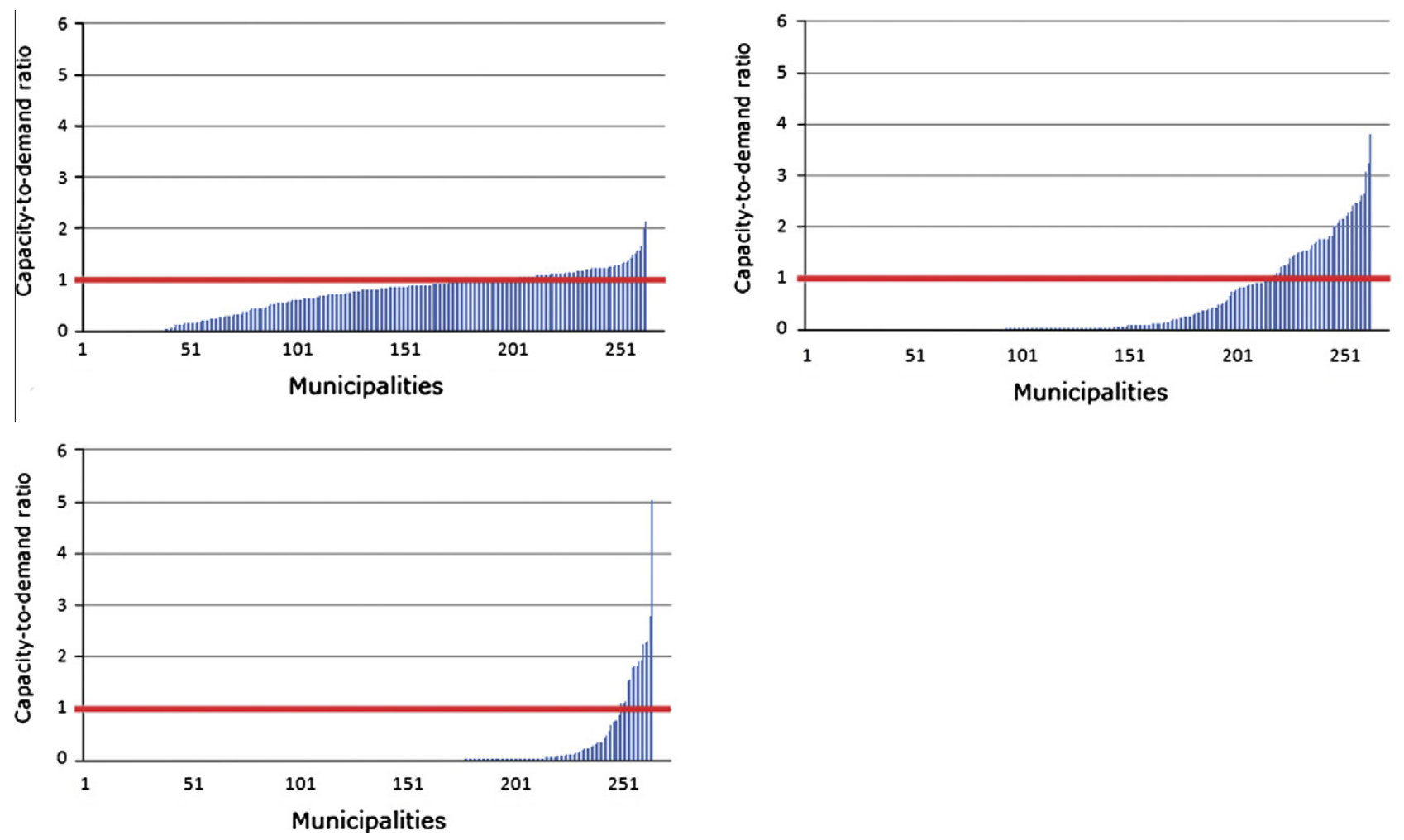

Fig. 8. The educational capacity-to-demand ratio (number of places/number of students living in the municipality) of the 262 municipalities of the Walloon region for nursery and primary schools (top left), secondary schools (top right) and tertiary institutions (bottom left).

Table 4

Spatial regression results

\begin{tabular}{|c|c|c|c|}
\hline & $\begin{array}{l}\text { Nursery and } \\
\text { primary schools } \\
r^{2}=0.268^{*} \\
\beta\end{array}$ & $\begin{array}{l}\text { Secondary } \\
\text { schools } \\
r^{2}=0.635^{*} \\
\beta\end{array}$ & $\begin{array}{l}\text { Tertiary } \\
\text { institutions } \\
r^{2}=0.519^{*} \\
\beta\end{array}$ \\
\hline Constant & $1.264^{*}$ & $1.500^{*}$ & $-0.534^{*}$ \\
\hline $\begin{array}{l}\text { Population } \\
\text { density (ln) }\end{array}$ & $-0.152^{*}$ & $-0.347^{*}$ & $-0.668^{*}$ \\
\hline $\begin{array}{l}\text { Share of active } \\
\text { commuting (ln) }\end{array}$ & $-0.498^{*}$ & $-0.500^{*}$ & $-0.412^{*}$ \\
\hline $\begin{array}{l}\text { School } \\
\quad \text { accessibility }(\ln )\end{array}$ & -0.008 & $-0.229^{*}$ & $-0.160^{*}$ \\
\hline Income $(\ln )$ & -0.074 & -0.074 & $0.130^{*}$ \\
\hline
\end{tabular}

greatest variability in energy consumed for commuting to secondary schools because secondary schools are spread throughout the region. In contrast, population density explained most of the variability in energy consumption for tertiary education, which largely takes place at institutions in city centres. The model failed to explain energy performance for commuting to nursery and primary schools, probably because the 5-kilometre range of the school accessibility index was not appropriate for this level of schooling. However, the data set did not allow for examination of smaller ranges. Mobility behaviour for nursery and primary schools relies more often on the individual choices of households than on the structure of the region. These results confirm the qualitative findings highlighted above through the assessment of map patterns.

\section{Reproducibility and opportunities for further study}

This paper examined the relationship between energy consumption for school commuting and spatial structure in the
Walloon region of Belgium. This work is reproducible in other regions and countries with the same characteristics (Europe) and should lead to the same observations. Moreover, in a territory larger than the Walloon region of Belgium (France, for example), the differences observed here should be even greater because of the same dynamics of concentration/decentralisation of primary/ secondary and tertiary institutions that coexist at larger scales.

Trip chaining is becoming increasingly more complex, but it was not examined in this paper. To some extent, chained trips could explain the lower modal share for active commuting and public transport for school commuting, especially when parents drive children to school on their way to work. Although it was not possible to study this phenomenon here because of limitations in the data set, the multivariate analysis suggested that nursery and primary schools would be good candidates for trip-chaining studies. Moreover, although school commuting is the primary reason children travel on weekdays, children's non-school mobility should also be studied for a more thorough understanding of their transport energy consumption. This idea will be explored in future research.

As stated in Section 2, the influence of urban form on transport energy consumption for school commuting is not the sole factor affecting travel distance. This paper focused on the links between energy consumption for school commuting and land-use patterns. Although the analyses presented here did not address external factors such as safety or poor walking environments, these factors may well influence adults' and children's mobility behaviours. In addition to the results presented in this paper, the impacts of these other factors should be investigated in further research involving the qualitative study of children's mobility.

\section{Conclusions}

This paper examined the relationship between transport energy consumption for school commuting and land-use patterns using 
two large-scale household travel surveys conducted in Belgium (Europe) in 1991 and 2001. Our findings confirm that urban form is an influential factor in school commuting and travel behaviour, and that mobility behaviours are dependent upon the location of residences and education infrastructure in the territory. This study found that student travel behaviours (transport mode choice and travel distance) are specific to the level of education. The concentration of tertiary educational institutions in urban centres leads to higher energy consumption, greater travel distances and less active commuting. Conversely, the decentralisation of nursery and primary schools throughout the region allows for very low local energy consumption and encourages more walking and cycling, although private car use remains important. The level of education seems to be a relevant index and should be considered together with the age of the children/youths being studied. To understand the mechanisms and logic underlying school commuting and to promote active/independent mobility strategies for children, it seems necessary to distinguish between (1) the type of urban form/neighbourhood and (2) the type of school/level of education, because these variables lead to different mobility patterns.

These results provide a greater understanding of children's travel behaviour and could therefore inform the development of effective policies and strategies focused on safe, sustainable and active travel to school. At the regional scale, policies concerning school locations should be studied at the living catchment scale and in relation to policies for public transport to favour shorter distances to and from primary schools and a greater use of public transport for secondary and tertiary institutions. In the same vein, current policies that require pupils to choose schools in their living basin should help to reduce energy consumption associated with school commuting. At the local scale, policies favouring active commuting to school should be implemented, as travel distances are small for primary and (to a lesser extent) secondary school students. These policies should deal with such aspects as the quality of public spaces, safety and the collective picking-up of pupils. Finally, the location of new residential districts in the region should also be examined in the light of the mobility patterns highlighted in this paper.

\section{Acknowledgements}

This research was funded by the Walloon region of Belgium (DGO4 - Department of Sustainable Building and Energy) as part of the "Suburban Areas Favouring Energy efficiency" Project (SAFE).

\section{References}

Banister, D. 1992. Energy use, transport and settlement patterns, In: Breheny, M. (Ed.), Sustainable Development and Urban Form. Pion Ltd., London, pp. 160181.

Banister, D., 1998. Sustainable development and transport. Report for the Bundesforschungsantalt für Landeskunde und Raumordnung. The URBAN 21 project.

Boarnet, M.G., Crane, R., 2001. Travel behaviour. In: Goodchild, M.F., Burrough, P.A., McDonnell, R.A., Switzer, P. (Eds.), Travel by Design. The Influence of Urban Form on Travel. Oxford University Press, New York, pp. 17-108.

Boussauw, K., Witlox, F., 2009. Introducing a commute-energy performance index for Flanders. Transportation Research Part A: Policy and Practice 43, 580-591.

Boussauw, K., Witlox, F., 2011. Linking expected mobility production to sustainable residential location planning: some evidence from Flanders. Journal of Transport Geography 19 (4), 936-942.

Breheny, M., 1995. The compact city and transport energy consumption. Transactions of the Institute of British Geographers 20 (1), 81-101.

Buliung, R., Sultana, S., Faulkner, G., 2012. Guest editorial: special section on child and youth mobility - current research and nascent themes. Journal of Transport Geography 20, 31-33.

Buliung, R.N., Mitra, R., Faulkner, G., 2009. Active school transportation in the greater Toronto area, Canada: an exploration of trends in space and time (19862006). Preventive Medicine 48, 507-512.
Cervero, R., Sarmiento, O.L., Jacoby, E., Fernando Gomez, L., Neiman, A., 2009. Influences of built environments on walking and cycling: lessons from Bogota. International Journal of Sustainable Transportation 3 (4), 203-226.

Dellinger, A.M., Staunton, C.E., 2002. Barriers to children walking and bicycling to school - United States, 1999. Morbidity and Mortality Weekly 51 (32), 701-704.

Department for Transport, 2005. Focus on Personal Travel: England. 2005 ed. London: TSO.

Dujardin, S., Pirart, F., Brevers, F., Marique, A.-F., Teller, J., 2012. Home-to-work commuting, urban form and potential energy savings: a local scale approach to regional statistics. Transportation Research Part A: Policy and Practice 46 $1054-1065$.

European Commission, 2008. European energy and transport - trends to 2030 European Commission, Luxemburg.

Ewing, R., Cervero, R., 2010. Travel and the built environment. Journal of the American Planning Association 7 (3), 265-294.

Ewing, R., Schroeer, W. Greene, W., 2004. School location and student travel: analysis of factors affecting mode choice. Transportation Research Record 1895 55-63.

Faulkner, G.E.J., Richichi, V., Buliung, R.N., Fusco, C., Moola, F., 2010. What's quickest and easiest? Parental decision making about school trip mode. International Journal of Behavioral Nutrition and Physical Activity 7, 1-11.

Feng, J., Glass, T.A., Curriero, F.C., Steward, W.F., Schwartz, B.S., 2010. The built environment and obesity: a systematic review of the epidemiologic evidence. Health \& Place 16, 175-190.

Fusco, C., Moola, F., Faulkner, G., Buliung, R., Richichi, V., 2012. Toward an understanding of children's perceptions of their transport geographies: (non) active school travel and visual representations of the built environment. Journal of Transport Geography 20, 62-70.

Gilbert, R., O'Brien, C., 2005. Child- and Youth-Friendly Land-Use and Transport Planning Guidelines. The Centre for Sustainable Transportation, Toronto.

Gordon, P., Richardson, H.W., 1989. Gasoline consumption and cities - a reply. Journal of the American Planning Association 55, 342-345.

Gordon, P., Richardson, H.W., 1997. Are compact cities a desirable planning goal? Journal of the American Planning Association 63 (1), 95-106

Hillman, M., Adams, J., Whitelegg. J., 1990. One false move ... A Study of Children's Independent Mobility. Policy Studies Institute, London.

Holloway, S.L., Valentine, G. (Eds.), 2000. Children’s Geographies: Playing, Living, Learning. Routledge, London.

Line, T., Chatterjee, K., Lyons, G., 2010. The travel behaviour intentions of young people in the context of climate change. Journal of Transport Geography 18, 238-246.

Marique, A.F., Reiter, S., 2011. Urban sprawl and travel energy consumption: the case of the Walloon region of Belgium. In: Proceedings of the Irish Transport Research Network Conference, Energy \& Transport, Programme and Proceedings, Ireland, University College Cork, 31 st August- $1^{\text {st }}$ September.

Marique, A.F., Reiter, S., 2012. A method for evaluating transport energy consumption in suburban areas. Environmental Impact Assessment Review 33 (1), 1-6.

McDonald, N.C., 2005. Getting to school: the impact of free transit on low income and minority students. Annual Meeting of the Transportation Research Board. Washington, DC

McDonald, N.C., 2012. Is there a gender gap in school travel? An examination of US children and adolescents. Journal of Transport Geography 20, 80-86.

McDonald, N.C., Aalborg, A.E., 2009. Why parents drive children to school. Journal of the American Planning Association 75 (3), 331-342.

McDonald, N.C., Brown, A.L., Marchetti, L.M., Pedroso, M.S., 2011. US school travel, 2009: an assessment of trends. American Journal of Preventive Medicine 41 (2) 146-151.

McMillan, T.E., 2005. Urban form and a child's trip to school: the current literature and a framework for future research. Journal of Planning Literature 19, 440-456.

McMillan, T.E., 2006. The relative influence of urban form on a child's travel mode to school. Transportation Research Part A 41, 69-79.

McMillan, T., Day, K., Boarnet, M., Alfonzo, M., Anderson, C., 2006. Johnny walks to school - does Jane? Sex differences in children's active travel to school. Children, Youth and Environments 16 (1), 75-89.

Mindali, O., Raveh, A., Salomon, I., 2004. Urban density and energy consumption: a new look at old statistics. Transportation Research Part A: Policy and Practice $38,143-162$.

Mitra, R., Buliung, R.N., 2012. Built environment correlates of active school transportation: neighborhood and the modifiable areal unit problem. Journal of Transport Geography 20, 51-61.

Mitra, R., Buliung, R.N., Roorda, M.J., 2010. The built environment and school travel mode choice in Toronto, Canada. Transportation Research Record 2156, 2150 2159.

Muniz, I., Galindo, A., 2005. Urban form and the ecological footprint of commuting. The case of Barcelona. Ecological Economics 55, 499-514.

Nayak, A., 2003. "Through children's eyes": childhood, place and fear of crime. Geoforum 34, 303-315.

Newman, P., Kenworthy, J.R., 1989. Cities and Automobile Dependence. A Sourcebook. Gower Publishing Co., Aldershot.

Newman, P., Kenworthy, J.R., 1999. Sustainability and Cities: Overcoming Automobile Dependence. Island Press, Washington, DC.

Saelens, B.E., Handy, L., 2008. Built environment correlates of walking: a review. Medicine \& Science on Sports \& Exercise 40, 550-566.

Sjolie, A.N., Thuen, F., 2002. School journeys and leisure activities in rural and urban adolescents in Norway. Health Promotion International 17 (1), 21-30. 
Stead, D., 2001. Relationships between land-use, socio-economic factors and travel patterns in Britain. Environment and Planning B: Planning and Design 28, 499-528. Susilo, Y.O., Waygood, E.O.D., 2012. A long term analysis of the mechanisms underlying children's activity-travel engagements in the Osaka metropolitan area. Journal of Transport Geography 20, 41-50.

Timperio, A., Ball, K., Salmon, J., Roberts, R., Giles-Corti, B., Simmons, D., Bauer, L.A., Crawford, D. 2006. Personal, family, social and environmental correlates of active commuting to school. American Journal of Preventive Medicine 30, 45-51.

Tranter, P., Sharpe, S., 2012. Disney-Pixar to the rescue: harnessing positive affect for enhancing children's active mobility. Journal of Transport Geography 20, $34-40$

Trapp, G.S.A., Giles-Corti, B., Christian, H.E., Bulsara, M., Timperio, A.F., McCormack, G.R., Villanueva, K.P., 2011. Increasing children's physical activity: individual, social and environmental factors associated with walking to and from school. Health Education and Behaviour 39 (2), 172-182.

United Nations, 2011. FAQs: social development, United Nations Youth Social Policy and Development Division. <http://social.un.org/index/Youth/FAQs.aspx> (accessed 29.2.2012)

Van der Ploeg, H., Merom, D., Corpuz, G., Bauman, A., 2008. Trends in Australian children traveling to school 1971-2003: burning petrol or carbohydrates? Preventive Medicine 46, 60-62.

Yeung, J., Wearing, S., Hills, A.P., 2008. Child transport practices and perceived barriers in active commuting to school. Transportation Research Part A 42, 895-900.

Ziviani, J., Scott, J., Wadley, D., 2004. Walking to school: incidental physical activity in the daily occupations of Australian children. Occupational Therapy International $11(1), 1-11$. 